\title{
25 Research Square \\ One-Stop Clinic for Patients with Suspected Ovarian Cancer Pathway from a Retrospective Outcome Study
}

Ayisha Adeeba Ashmore ( $\square$ a.kibria@doctors.org.uk)

University Hospitals of Leicester NHS Trust https://orcid.org/0000-0003-1011-6253

C. Gnanachandran

Northampton General Hospital

I. Luqman

Northampton General Hospital

K. Horrocks

Northampton General Hospital

Research article

Keywords: Ultrasound Scanning, Ovarian Cancer, Cancer Screening, Tumour markers, Clinical Effectiveness

Posted Date: August 17th, 2020

DOI: https://doi.org/10.21203/rs.3.rs-42449/v1

License: (9) (1) This work is licensed under a Creative Commons Attribution 4.0 International License.

Read Full License 


\section{Abstract}

\section{Background:}

Recent encouragement in early detection of cancer nationally has significantly increased the number of referrals made through the two-week wait suspected cancer pathway. In particular women with abdominal pain and bloating are frequently having their Ca-125 levels investigated for suspected ovarian cancer and this has led to a significant increase in referrals to the ovarian cancer service. We have conducted this study to help improve the efficiency in which these patients are investigated and to improve future pathways within the referral service.

\section{Methods:}

A retrospective observational outcome study. Data were collected from electronic documents of patients' referrals, assessments, and clinical correspondences.

The study was conducted in a tertiary gynaecology cancer centre with primary care direct referrals. The pelvic mass clinic was the clinic setup with consultation, scan and patient support was available. All patients referred by direct primary care for suspected ovarian cancer over two years with Ca-125 result.

Data were collected and analysed from the pelvic mass clinic over 48 months, which was available through electronic documentation. Data included information on their consultation, ultrasound scan findings, any further intervention, surgery, and histological outcome of all patient who underwent biopsies or surgery.

\section{Results:}

Two hundred and eighty-six patients were referred from primary care where the NICE guideline, 'two-week wait for ovarian cancer', was applied.

Two hundred and twenty-three patients were included in this analysis, who had a Ca-125 result reported at the time of their referral. Out of the 223 patients, 126 patients were discharged with or without a repeat Ca-125 after the initial assessment. Seventeen patients were diagnosed with cancer following the referral, but only 12 of them had a primary ovarian malignancy.

\section{Conclusion:}

Majority of the patients with Ca-125 of more than $35 \mathrm{U} / \mathrm{mL}$, who were referred through this pathway, did not have cancer. This message can be disseminated by primary care practitioners who may be able to reassure patients prior to their initial consultation with a gynaecologist.

This review queries the future value of using $\mathrm{Ca}-125$ as the basis for referrals from primary care referrals for suspected ovarian malignancy. Further studies are required to assess whether a higher Ca-125 cut off may be used as the basis of referrals for postmenopausal women. 
One-stop focused gynaecology ultrasound clinic (OSFGUC) where clinicians may assess patients with suspected ovarian cancer symptoms and perform ultrasound scans may be better for managing this patient population.

\section{Background:}

Around 7000 women are diagnosed with ovarian cancer every year in the UK with a significant proportion presenting with advanced disease ${ }^{1}$. The average, five-year survival rate in the UK is $46 \%$, which is lower than the European five-year survival rate for ovarian cancer. The early diagnosis of primary ovarian malignancy is paramount in increasing the rate of five-year survival. For example, when diagnosed in the initial stages, $90 \%$ of women will survive for at least five years, contrasted to a five-year survival of under $50 \%$ when diagnosed in the latest stage ${ }^{1}$.

The NICE referral pathway for primary care for suspected ovarian cancer has recommended a Ca-125 measurement as part of the '2-week wait suspected cancer pathway' in 2011, 2015 and 20172-3. NICE adopted Ca-125, which has long been associated with female reproductive tract pathology, as a tool to identify women at risk.

Ca-125 is a glycoprotein which is a component of the gastrointestinal tract, the respiratory tract, and the female reproductive tract. Since its discovery in 1981, serum Ca-125 has been associated with both benign and malignant female reproductive tract pathology ${ }^{6,7}$. Raised Ca-125 is associated with ovarian cancer and has been used as a serum marker for ovarian cancer ${ }^{4}$. Preoperative Ca-125 is an independent risk factor and helps in decision-making models ${ }^{8,9.10}$. However, marginally increased levels are not disease-specific and are poorly correlated with the diagnosis of ovarian malignancy 4,5,11. Besides, serum Ca-125 is frequently within normal limits seen in some early ovarian cancers.

Nationally there has been a drive to promptly refer patients for further investigation and treatment for suspected ovarian cancer. The introduction of Ca-125 as a referral criterion has significantly increased the number of referrals for further investigation. Current referral criteria have resulted in an enormous increase in demand for the investigation of suspected gynaecological malignancies with patients arrive with anxiety and stress.

Our study is possibly the first to review the effectiveness and efficiency of a one-stop focused gynaecology ultrasound clinic (OSFGUC) for suspected ovarian cancers. When a patient is referred via the primary care pathway, they are reviewed initially in the OFGUSC for complete assessment by a consultant gynaecologist. Our practice involves using ultrasonography to fully assess patients as part of the initial examination, thereby expediting diagnosis and enhancing the patient pathway.

\section{Methods:}


We conducted a retrospective outcome-based observational study using data from electronic documents at Northampton General Hospital. The OFGUSC involves a consultation, including sonographic assessment by a consultant gynaecologist, followed by the formulation of a plan for discharge, further investigation, or surgery.

Data were collected from all patients referred from the region to the two-week wait clinic for suspected ovarian cancer over two years (August 2016-August 2018). Patients, who were referred from other regional hospitals for treatment of adnexal masses or confirmed diseases were excluded. The total number of patients seen through direct ovarian cancer two-week wait pathway was 286 .

Patients included in the study had symptoms such as pain, bloating or discomfort with or without a raised $\mathrm{Ca}-125$. Patients who were referred with only a raised $\mathrm{Ca}-125$ without prominent ovarian cancer symptoms were also included in the study analysis. Patients with a palpable pelvic mass but no Ca-125 result at the time of referral were excluded. The total number of patients included in our analysis was 223.

Our outcome measures included discharge after the first appointment, scheduled follow-ups, operative intervention, and final histologic diagnosis following surgery.

Although data based on the IOTA principles ${ }^{13}$ were collected, an analysis was not performed due to low numbers of patients for conclusions.

\section{Results:}

The total number of patients included in our analysis was 223. One hundred and forty-four (144) patients were aged 50 years or above (65\%). Seventy-nine (79) patients were aged below 50 (35\%).

The primary reason for referral to the pathway (Table 1: Reason for referral based on age group) was the identification of an elevated serum $\mathrm{Ca}-125$, by a primary care physician, along with either pelvic pain, discomfort or sensation of abdominal/pelvic mass. 
Table 1

Reason For referral based on age group

\begin{tabular}{|llll|}
\hline Reason for Referral & $\begin{array}{l}\text { Age } \\
<50\end{array}$ & $\begin{array}{l}\text { Age 50 and } \\
\text { above }\end{array}$ & $\begin{array}{l}\text { Grand } \\
\text { Total }\end{array}$ \\
\hline Bloating & 9 & 9 & 125 \\
\hline $\begin{array}{l}\text { Raised Ca-125 }(>35 \mathrm{U} / \mathrm{mL}) \text { with or without specific } \\
\text { symtoms }\end{array}$ & 44 & 81 & 13 \\
\hline Incidental Cyst & 2 & 11 & 45 \\
\hline Mass & 17 & 28 & 19 \\
\hline Pain & 9 & 10 & 12 \\
\hline Other & 7 & 5 & $\mathbf{2 2 3}$ \\
\hline Grand Total & $\mathbf{7 9}$ & $\mathbf{1 4 4}$ & \\
\hline
\end{tabular}

An elevated serum Ca-125 was observed in 81 out of 144 patients (56\%) aged 50 or over and in 44 out of 79 patients (56\%) aged below 50 . The remaining patients, in both age groups, were referred to the clinic with specific symptoms only and were found to have a Ca-125 below $35 \mathrm{U} / \mathrm{mL}$ (Table 2: Ca-124 level based on age group).

Table 2

Ca-125 level by age group

\begin{tabular}{|llll|}
\hline Ca-125 Level $(\mathbf{U} / \mathbf{m L})$ & Age $<\mathbf{5 0}$ & Age $\mathbf{5 0}$ and above & Grand Total \\
\hline Normal $(<35)$ & 31 & 57 & 88 \\
\hline $35-69$ & 48 & 87 & 135 \\
\hline $70-99$ & 26 & 38 & 64 \\
\hline$>100$ & 13 & 28 & 41 \\
\hline Grand Total & $\mathbf{7 9}$ & $\mathbf{1 4 4}$ & $\mathbf{2 2 3}$ \\
\hline
\end{tabular}

Forty-four patients (20\%) had surgical interventions following their initial consultation and ultrasound scan in OSC, with or without further imaging. Fifteen patients underwent laparoscopic surgeries (including salpingo-oophorectomy or ovarian cystectomy). Twenty-five patients underwent major surgeries (such as total abdominal hysterectomy + /- bilateral salpingo-oophorectomy and omentectomy). Only four patients had a total laparoscopic hysterectomy or open hysterectomy for benign disease.

Of 223 patients included in the study, only 18 (8\%) were diagnosed with a malignancy which was confirmed histologically. Out of these 18 , only 12 patients were identified as having a primary ovarian malignancy. The other six malignancies were primary cancers from the gastrointestinal tract or metastases from other abdominal primary cancers (Table 3: histological outcome based on Ca-125). 
Table 3

Histological outcome based on Ca-125

\begin{tabular}{|c|c|c|c|}
\hline Histological Outcome & $\mathrm{Ca}-125<35 \mathrm{U} / \mathrm{mL}$ & $\begin{array}{l}\mathrm{Ca}-125 \\
>35 \mathrm{U} / \mathrm{mL}\end{array}$ & $\begin{array}{l}\text { Grand } \\
\text { Total }\end{array}$ \\
\hline $\begin{array}{l}\text { Benign Pelvic Disorders (including } \\
\text { inflammatory disorders) }\end{array}$ & 19 & 14 & 30 \\
\hline $\begin{array}{l}\text { Benign Uterine Disorders (including } \\
\text { fibroids) }\end{array}$ & 16 & 23 & 38 \\
\hline Uterine Malignancy & 0 & 1 & 1 \\
\hline \multirow[t]{2}{*}{ Ovarian Malignancy } & 5 & 7 & 12 \\
\hline & $\begin{array}{l}\text { ( } 2 \text { bordeline, } 1 \text { gercell tumor, } 1 \text { - } \\
\text { Stuma Ovari and } 1 \text { - FIGO 1a) }\end{array}$ & & \\
\hline $\begin{array}{l}\text { Abdominal malignancy but not } \\
\text { related to reproductive organs }\end{array}$ & 2 & 3 & 5 \\
\hline $\begin{array}{l}\text { No significant pelvic or abdominal } \\
\text { pathology }\end{array}$ & 56 & 87 & 137 \\
\hline Grand Total & 86 & 135 & 223 \\
\hline
\end{tabular}

We performed further analysis (Table 3,4,5) to consider whether a higher cut-off value for referrals using $\mathrm{Ca}-125$ would lead to fewer malignancies being identified. Increasing the referral threshold value of Ca$125 \mathrm{from} 35 \mathrm{U} / \mathrm{mL}$ to either 70 or $100 \mathrm{U} / \mathrm{mL}$ was retrospectively explored to identify the rate of missed malignancies.

Table 4

Histological outcome based on Ca-125 >70U/mL

\begin{tabular}{|c|c|c|c|}
\hline Histological Outcome & Ca-125 <70U/mL & $\begin{array}{l}\text { Ca-125 } \\
>70 U / m L\end{array}$ & $\begin{array}{l}\text { Grand } \\
\text { Total }\end{array}$ \\
\hline $\begin{array}{l}\text { Benign Pelvic Disorders (including } \\
\text { inflammatory disorders) }\end{array}$ & 17 & 13 & 30 \\
\hline Benign Uterine Disorders (including fibroids) & 25 & 13 & 38 \\
\hline Uterine Malignancy & 0 & 1 & 1 \\
\hline Ovarian Malignancy & $\begin{array}{l}5^{\star}(\text { see above of the types } \\
\text { and stage) }\end{array}$ & 7 & 12 \\
\hline $\begin{array}{l}\text { Abdominal malignancy but not related to } \\
\text { reproductive organs }\end{array}$ & 2 & $3^{\star}$ & 5 \\
\hline $\begin{array}{l}\text { No significant pelvic or abdominal } \\
\text { pathology }\end{array}$ & 100 & 37 & 137 \\
\hline Grand Total & 150 & 74 & 223 \\
\hline
\end{tabular}


We found that at the level of Ca- 125 of $70 \mathrm{U} / \mathrm{mL}$, one non-ovarian cancer would not have been referred, however, if a value of $100 \mathrm{U} / \mathrm{mL}$ were used, five additional malignancies would have been missed.

Table 5

Histological Outcome Ca-125 >100U/mL

\begin{tabular}{|llll|}
\hline Histological Outcome & $\begin{array}{l}\text { Ca-125 } \\
<100 \mathrm{UL} / \mathrm{mL}\end{array}$ & $\begin{array}{l}\text { Ca-125 } \\
\mathbf{1 0 0 U} / \mathrm{mL}\end{array}$ & $\begin{array}{c}\text { Grand } \\
\text { Total }\end{array}$ \\
\hline $\begin{array}{l}\text { Benign Pelvic Disorders (including inflammatory } \\
\text { disorders) }\end{array}$ & 26 & 4 & 30 \\
\hline $\begin{array}{l}\text { Benign Uterine Disorders (including fibroids) } \\
\text { Uterine Malignancy }\end{array}$ & 33 & 5 & 38 \\
\hline Ovarian Malignancy & 1 & 2 & 1 \\
\hline $\begin{array}{l}\text { Abdominal malignancy but not related to } \\
\text { reproductive organs }\end{array}$ & 10 & 1 & 12 \\
\hline No significant pelvic or abdominal pathology & 101 & 36 & 5 \\
\hline Grand Total & 176 & $\mathbf{4 8}$ & $\mathbf{2 2 3}$ \\
\hline
\end{tabular}

\section{Discussion:}

Our study is the first to report on the outcomes of an ovarian cancer referral pathway from the community to secondary care based on one-stop focused gynaecology ultrasound clinic (OSFGUC). The OSFGUC clinic not only expedites the diagnosis of malignancy but may alleviate patient anxiety when being investigated for suspected malignancy if ultrasound scans are not suggestive of sinister pathology.

We found that our one-stop focused gynaecology ultrasound clinic (OSFGUC) was highly effective in the management of an increased patient burden by way of offering a service that provides same-day full assessment, definitive diagnosis, and management plan. As the results suggest, almost one-third of patients were able to be discharged directly from the clinic following their initial appointment followed up by primary care for repeat $\mathrm{Ca} 125$ in acceptable but individualised for patient care.

Our study has demonstrated that raising the referral criteria from a Ca- 125 of $35 \mathrm{U} / \mathrm{mL}$ to $70 \mathrm{U} / \mathrm{mL}$, for the suspected ovarian cancer pathway, reduced the number of patients who may not have needed a direct referral to cancer services. We feel that these patients should be referred, instead, for a pelvic ultrasound to exclude pelvic pathology. If a new cut-off of $70 \mathrm{U} / \mathrm{mL}$, particularly for premenopausal women, were implemented, a significant proportion of patients would not be referred to the suspected cancer clinic. By using a higher value of Ca-125 for premenopausal women as a threshold for referral, we may reduce the burden on gynaecology services. A higher threshold of Ca125 for referral, in turn, prevent unnecessary, anxiety-inducing referrals of young women to gynaecology clinics with conditions such as endometriosis. 
While our approach could be replicated in other centres and units for gynaecology malignancies, several limitations must be considered.

Our study has a small sample size and therefore lacks generalisability. We are currently collecting further data to strengthen our conclusions with regards to this matter. Further, if our model could be replicated, a clinic with ultrasound scanning facilities would be required with training on scanning and accreditation for gynaecology scanning.

While our model for ovarian cancer pathway demonstrates a more streamlined and rapid assessment of the discussed cohort of patients, it does not necessarily follow that such a service offers value for money. A cost analysis would be useful in determining how efficient this pathway would be in comparison to current practice.

Finally, for patients who had high Ca-125 but normal pelvis on the scan, a repeat Ca-125 was performed if needed by their general practitioner. If Ca-125 continued to rise, then they were re-referred to clinic for further advice and management. We aim to report the number of patients who needed further follow up and their two years outcome in our subsequent studies.

The lack of specificity of Ca-125, especially in premenopausal women and validity of ultrasonic features of adnexal mass for prediction of malignancy is well-documented ${ }^{11,12,13}$. We recommend that patients with symptoms suspicious of ovarian cancer should be referred to a clinic where scan facilities available as part of the initial consultation. Further research is also required to establish whether a higher referral threshold value for $\mathrm{Ca}-125$ is safe if ultrasound facilities are available for normal to marginally high ca 125 through another pathway

\section{Conclusion:}

The one-stop focused gynaecology ultrasound clinic (OSFGUC) has been instrumental in helping to manage a substantial number of referrals and provides a timely diagnosis of ovarian pathology. It permits a vast majority of patients to be discharged from the two-week wait pathway back to the primary care with further monitoring of tumour markers and or repeat scan in some patients.

At present, NICE guidance suggests that a serum Ca- $125>35 \mathrm{U} / \mathrm{mL}$ should be the threshold at which a patient is referred from primary care to gynaecology services. The optimal threshold for referrals has never been determined ${ }^{6}$. Future studies should explicitly examine the correlation of serum Ca-125, in conjunction with symptomology and ultrasonography, with final histologic diagnoses. This would better characterise the role of this tumour marker in identifying those at high risk of ovarian malignancy and would permit further optimisation the primary care referral process.

The UK ROckETS study ${ }^{15}$ may be able to answer several questions regarding the combined use Ca-125, other biomarkers and IOTA principles-based ultrasound scans in characterising the individual risk of 
ovarian malignancy. Developing a validated risk scoring model will optimisation of the referral process, reduce clinic burden and fast track the patients who need urgent treatment.

\section{Abbreviations}

NICE: National Institute for Health and Care Excellence

OSFGUC: one-stop focused gynaecology ultrasound clinic

\section{Declarations}

\section{Ethics Approval and Consent to Participate}

- Access and permission for use of medical records were obtained from the Clinical Governance and Audit Department at Northampton General Hospital. No ethics approval was required as study was conducted retrospectively as part of an audit and service evaluation project and does not constitute research as per the Medical Research Council UK.

\section{Consent for Publication}

- Not applicable

\section{Competing Interests}

- The authors declare that they have no competing interests.

\section{Funding}

- There is no funding allocated for this retrospective study. Authors completed the study on their own time.

\section{Availability of Data and Materials}

- The datasets used and/or analysed during the current study are available from the corresponding author on reasonable request.

\section{Authors' contributions}


- AAA collected, analysed and interpreted all data gathered and a major contributor in writing the manuscript. CG conceived the idea for the study and was a significant contributor to the analysis of the data. He is a significant contributor in writing the manuscript. IL and $\mathrm{KH}$ helped in data collection. All authors read and approved the final manuscript.

\section{Acknowledgements}

- Not applicable

\section{References}

1. Cancer Research UK, Ovarian Cancer Statistics. https://www.cancerresearchuk.org/healthprofessional/cancer-statistics/statistics-by-cancer-type/ovarian-cancer/incidence\#heading-Zero. [Accessed 16 September 2019].

2. NICE guidance. Ovarian cancer: recognition and initial management. Clinical guideline [CG122]. Published April 2011. Available on https://www.nice.org.uk/guidance/cg122/evidence/full-guidelinepdf-181688799, [Accessed on $28^{\text {th }}$ March 2020]

3. NICE guidance.Gynaecological cancers - recognition and referral. Available on https://cks.nice.org.uk/gynaecological-cancers-recognition-and-referral\#!scenario. Last revised in November 2016. Last [Accessed on 31st March 2020]

4. Bast RC, Feeney M, Lazarus H, Nadler LM, Colvin RB, Knapp RC (1981). Reactivity of a monoclonal antibody with human ovarian carcinoma. The Journal of Clinical Investigation. 68(5), 1337-7.

5. Park, Y., Lee, J.H., Hong, D.J., Lee, E.Y. and Kim, H.S., (2011). Diagnostic performances of HE4 and CA125 for the detection of ovarian cancer from patients with various gynecologic and nongynecologic diseases. Clinical biochemistry. 44(10-11), 884-888.

6. Medeiros, L. R., Rosa, D. D., da Rosa, M. I., \& Bozzetti, M. C. (2009). Accuracy of CA 125 in the diagnosis of ovarian tumors: A quantitative systematic review. European Journal of Obstetrics \& Gynecology and Reproductive Biology. 142(2), 99-105. doi:10.1016/j.ejogrb.2008.08.011

7. McIntosh, M. W., Drescher, C., Karlan, B., Scholler, N., Urban, N., Hellstrom, K. E., \& Hellstrom, I. (2004). Combining CA 125 and SMR serum markers for diagnosis and early detection of ovarian carcinoma. Gynecologic oncology. 95(1), 9-15. doi:10.1016/j.ygyno.2004.07.039 Medeiros LR, Rosa DD, da Rosa MI, Bozzetti MC. Accuracy of CA 125 in the diagnosis of ovarian tumors: a quantitative systematic review. European Journal of obstetrics \& gynecology and Reproductive Biology. 2009 Feb 1;142(2):99-105.

8. Cooper BC, Sood AK, Davis CS, Ritchie JM, Sorosky JI, Anderson B, Buller RE. Preoperative CA 125 levels: an independent prognostic factor for epithelial ovarian cancer. Obstetrics \& Gynecology. 2002 Jul 1;100(1):59-64. 
9. Sölétormos G, Duffy MJ, Hassan So, Verheijen RH, Tholander B, Bast RC, Gaarenstroom KN, Sturgeon CM, Bonfrer JM, Petersen PH, Troonen H. Clinical use of cancer biomarkers in epithelial ovarian cancer: updated guidelines from the European Group on Tumor Markers. International Journal of Gynecologic Cancer. 2016 Jan 1;26(1):43-51.

10. Lycke M, Kristjansdottir B, Sundfeldt K. A multicenter clinical trial validating the performance of HE4, CA125, risk of ovarian malignancy algorithm and risk of malignancy index. Gynecologic oncology. 2018 Oct 1;151(1):159-65.

11. Medeiros LR, Rosa DD, da Rosa MI, Bozzetti MC. Accuracy of CA 125 in the diagnosis of ovarian tumors: a quantitative systematic review. European Journal of obstetrics \& gynecology and Reproductive Biology. 2009 Feb 1;142(2):99-105.

12. Dodge JE, Covens AL, Lacchetti C, Elit LM, Le T, Devries-Aboud M, Fung-Kee-Fung M, Gynecology Cancer Disease Site Group. Preoperative identification of a suspicious adnexal mass: a systematic review and meta-analysis. Gynecologic oncology. 2012 Jul 1;126(1):157-66

13. Timmerman, D., Valentin, L., Bourne, T.H., Collins, W.P., Verrelst, H. and Vergote, I., 2000. Terms, definitions and measurements to describe the sonographic features of adnexal tumors: a consensus opinion from the International Ovarian Tumor Analysis (IOTA) Group. Ultrasound in Obstetrics and Gynecology: The Official Journal of the International Society of Ultrasound in Obstetrics and Gynecology. 16(5), 500-505.

14. Jacobs, I.J., Menon, U., Ryan, A., Gentry-Maharaj, A., Burnell, M., Kalsi, J.K., Amso, N.N., Apostolidou, S., Benjamin, E., Cruickshank, D. and Crump, D.N., (2016). Ovarian cancer screening and mortality in the UK Collaborative Trial of Ovarian Cancer Screening (UKCTOCS): a randomised controlled trial. The Lancet. 387(10022),945-956.

15. Sundar, S., Rick, C., Dowling, F., Au, P., Snell, K., Rai, N., Champaneria, R., Stobart, H., Neal, R., Davenport, C. and Mallett, S., 2016. Refining Ovarian Cancer Test accuracy Scores (ROCkeTS): protocol for a prospective longitudinal test accuracy study to validate new risk scores in women with symptoms of suspected ovarian cancer. BMJ open. 6(8), 010333. 